\title{
Colour-blind attitudes of students at the North-West University, Potchefstroom Campus
}

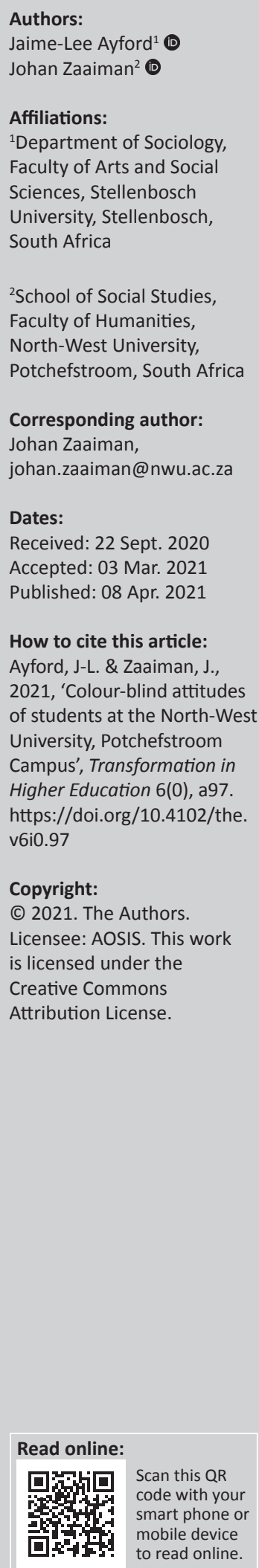

Background: Colour-blind attitudes deny racial dynamics and can lead to resistance to transformation because there seems to be no need for it. This study investigated these attitudes amongst students at a university campus engaged with implementing its transformation agenda.

Aim: Using a survey, the research determined the prevalence of colour-blind attitudes amongst students and evaluated the social factors that may have contributed to these attitudes.

Setting: The research was conducted amongst undergraduates at the North-West University, Potchefstroom Campus, South Africa, in 2017.

Methods: A literature review was conducted around the occurrence of colour-blind attitudes amongst students and the associated social factors. Race, gender, racial prejudice, just-world beliefs and social dominance orientation in particular were found to contribute to colour-blind attitudes. A quantitative survey was then conducted amongst a quota sample of 300 students. The data collected on the social factors and colour-blind attitudes were statistically analysed.

Results: The students' colour-blind attitudes were found to be moderate. The social factor of race correlated significantly with colour-blind attitudes, but gender did not. Racial prejudice presented a medium correlation with colour-blind attitudes but just-world beliefs and social dominance orientation only a small correlation.

Conclusion: Colour-blind attitudes at the campus were related to race and racial prejudice. This demonstrates the need for students to be offered room to openly discuss and engage with race and issues concerning race. The difference between the findings in this study and extant literature indicates a necessity for further qualitative research to gain a more comprehensive understanding about racial issues amongst students at the North-West University, Potchefstroom Campus.

Keywords: colour-blind attitudes; race; gender; racial prejudice; just-world beliefs; social dominance orientation; students; North-West University.

\section{Introduction}

The ultimate goal of transformation in South Africa has been to jettison its history of racial prejudice in favour of equality and non-discrimination. However, colour-blind attitudes minimise, distort and deny the reality of racism and the role that race plays in people's lives (Neville et al. 2014:180). The problem with such attitudes is that they can entrench existing societal hierarchies and inequalities at individual, interpersonal, cultural and institutional levels. The attitudes relate to a misconception of how the concept of race has been historically used to divide and discriminate against people. They furthermore ignore the fact of the continuation of racism and ways in which race influences people negatively in their everyday lives (Neville et al. 2000:60). Avoiding the matter of race, therefore, may actually contribute to the continuation of past inequalities (Kestner 2009:19). On the one hand, such continuation safeguards the interests and racial privileges of advantaged groups; on the other hand, disadvantaged groups are victimised when they are blamed or derogated for their backward position (Kestner 2009:9). This means that colour-blind attitudes can be defined as 'the denial of racial dynamics leading to an unawareness of the existence of racism' (McDonald 2016:12). In this context, the present study critically examines students' colour-blind attitudes on a South African university campus that is working towards successful implementation of its transformation agenda. This study is the first one in investigating the colour-blind attitudes and related social factors at a South African university and presents a unique application and analysis thereof.

Pearson, Dovidio and Geartner (2009:3) wrote about aversive racism related to colour-blind attitudes. In dominative racism, racial hatred is openly shown towards others and beliefs in 
racial superiority are supported. In the case of aversive or covert racism, the principle of racial equality is upheld but, simultaneously, negative feelings and beliefs about certain races are maintained. These feelings are expressed in disguised, private, insidious and rationalised ways (Coates 2011:1; Dovidio et al. 2009:4); and individual, institutional and cultural manifestations of racism are not acknowledged. Puttick (2011:5) refers to colour-blind attitudes as a kind of symbolic racism in which individuals can 'harbour racist beliefs whilst simultaneously practicing equality'. However, it should be noted that colour-blind attitudes can also be associated with individuals harbouring a genuine desire to move beyond racism. But, as noted above, the problem with such attitudes is that they may inadvertently retain the status quo and avoid confronting racism and its outcomes.

Contemporary South Africa is in transition from a past that was divided along racial, cultural and economic lines to a present and future that will be democratic and accepting of diversity (Amoateng \& Kalule-Sabiti 2014:623). In the past, racial politics had a major impact on South African society. Unfortunately, inequality, hurt and difference in life experiences continue along the lines of the former racial divisions. According to Greenstein (2015:173), despite efforts made to improve racial relations amongst South Africans, racism, discrimination and racial prejudice continue to manifest themselves in the public sphere. Because it has become socially unacceptable to explicitly show prejudicial attitudes, colour-blind attitudes may offer an alternative. They can, for instance, include delicate forms of racism and subtle and indirect forms of prejudice and intolerance (Mazzocco 2015:3). Thus, a 'new racism' can replace the old racism in South Africa but still, paradoxically, produce racial privilege in an apparently non-racial manner (Bonilla-Silva 2003:68). Neville et al. (2000) refer to several studies in educational and sociological literature that demonstrate the existence and effects of colour-blind attitudes in educational institutions. The student population in many South African universities is currently diverse as never before. Racial tensions with cultural undertones are, therefore, present. These can manifest amongst students as colour-blind attitudes that mask underlying prejudice.

This research focused on undergraduate students at the North-West University (NWU), Potchefstroom Campus, South Africa. The campus was viewed as ideal for this study for the following reasons. A Ministerial Task Team reported in 2008 that black and white students at the NWU differed strongly on issues of inclusion and exclusion (Kamsteeg 2011:56). Their report is linked to the finding of an internationally led evaluation of the NWU in 2013/2014, which found that, of the three campuses in the university, the Potchefstroom Campus was culturally the most homogeneous and least open to external social and political influences (Pretorius 2017:272). The evaluation, therefore, emphasised the necessity of developing an integrated NWU culture and identity (Prinsloo 2016:387). This relates to the NWU Transformation Charter (North-West University 2012) that presents the ideal of a transformation that nurtures inclusivity. Kamsteeg (2008:448) argued that, to bring about such a change in culture and identity, further study was required to identify the various areas of conflict and cooperation. The present research attempted to contribute to this task. As the Potchefstroom Campus is mainly an Afrikaans campus with mostly white students, alienation in language, symbols and culture have been organised along race identities. It is, therefore, important to understand the prevalence, amongst students, of their colour-blind attitudes because these can suppress debates about racial discrimination and hinder transformation, not only on this campus but also in the NWU as a whole.

\section{Social factors and their relationship with colour-blind attitudes}

A variety of factors contribute to colour-blind attitudes. To investigate this on the university campus, it is important to understand what factors may contribute to them. In this way, a better understanding can be developed about what interventions the transformation processes must focus on. This study focused on the factors of race, gender, racial prejudice, just-world beliefs and social dominance orientation. The choice of these factors is explained in the following subsections.

\section{Race}

Race was the first factor included in our study. Kamsteeg (2008:447) described the NWU Potchefstroom Campus as representing a culture of whiteness. In such a homogenic setting, the reality of racism and the role that race plays in people's lives can be suppressed. Yet the dropout and graduation rates between black and white students on the campus indicate differences in their university experience (Prinsloo 2016:319). Black students experienced cultural and social exclusion (Pretorius 2017:269). We, therefore, viewed it as valuable to determine whether white students were blinded to this reality by colour-blind attitudes that may hinder transformation.

In this study, race is understood as referring to physical features and their associated material practices and cultural meanings. Race relates, therefore, to the organisation and functioning of the society. However, it follows social dynamics in a fluid manner (Greenstein 2015:194). The connection between race and human differences links race with power relationships. South Africa has been notorious for its use of the idea of race to rationalise political segregation and resultant social inequalities. It is, however, problematic to believe that, in the new post-apartheid dispensation, race is no longer relevant in society. Such a notion constitutes colour-blindness, even as race still determines inequalities in the country (Greenstein 2015:174).

The argument to research race in this study was supported by other studies that found colour-blind attitudes to be more common amongst white people than amongst other groups (Neville et al. 2000:60). White people, adopting a colour-blind 
standpoint, may guard themselves against recognising racial inequalities in their society and thus lessen experiences of dissonance or awareness of own privilege. Thereby white people can uphold their positive self-esteem by suppressing ideas that undermine it (Neville et al. 2000:69). It is possible that black people can also have colour-blind perspectives (Burke 2019:83). This may make them unaware of racial discrimination and undermine working positively to address it (Neville et al. 2000:69).

In this research, students were asked to identify their race. Race in this article refers, therefore, to the students' selfidentification of their race as defined above. In the research, race was operationalised through a question in which students could mark the race with which they identified.

\section{Gender}

The second factor that we included in the study was gender. It was argued that for the transformation agenda at the NWU Potchefstroom Campus, it would be valuable to know whether male and female students differed in their colourblind attitudes. This was in view of literature reporting that compared to women, men express higher levels of intolerance, including increased homophobia; greater endorsement of social dominance orientation and negative assessments of policies planned to advance increased representation in the workplace (Neville et al. 2014:180). Such findings may relate to the privileged position of men in the social structure and their desire to protect this position. Also, men traditionally have less experience of societal oppression and thus may be less aware of its effects compared to women (Neville et al. 2014:180). Neville et al. (2000) found, in relation to the colourblind racial attitude scale (CoBRAS), that women are more sensitive to social injustices than their male counterparts. It may be that women on average are sensitised to institutional discrimination on the basis of gender and, thus, could be more aware of the existence of other types of discrimination, such as racism (Neville et al. 2000:68). It was, therefore, concluded that women's colour-blind attitudes are lower than men's (Neville et al. 2000:68). It is worth noting that the NWU Transformation Charter (North-West University 2012) is quiet about gender in transformation. We, therefore, viewed it as valuable to determine the applicability of the findings of Neville et al. (2000) on gender and to determine whether gender affected colour-blind attitudes.

Gender, as the social construction of what it means to be male or female (Rabe 2015:153), was, therefore, operationalised in our research through the self-identification by students in the questionnaire (see Appendix 1).

\section{Racial prejudice}

Another factor included in our research was racial prejudice because, if colour-blind attitudes are found to be related to racial prejudice, their problematic nature is revealed. The NWU Potchefstroom Campus was, historically, a conservative university supportive of apartheid ideology
(Kamsteeg 2008:444). Prinsloo (2016:331) reported a perception amongst NWU's management that the white students on the campus are prejudiced. We, therefore, viewed it as important for our study to determine the extent to which racial prejudice contributes to colour-blind attitudes.

Racial prejudice includes the maintenance of stereotypical views about people from other race groups. In the apartheid era, it became an integral aspect of South African society (Greenstein 2015:174). It relates to centuries of systematic exclusion, exploitation and cultural subversion (Winant 1998:758). It is the result of discrimination through individual actions or policies. Neville et al. (2000:68) found that colour-blind racism relates to the modern racism scale (MRS) and quick discrimination index, indicating that the higher one's racial prejudice against other groups, the more likely one would be to hold colour-blind attitudes. This is confirmed by the research of McConahay (1986), which demonstrated a significant positive relationship between CoBRAS and the MRS. Kestner (2009:19-20) also argues that rising psychological research on colour-blind racial attitudes highlights their relationship to racial prejudice. Those with colour-blind attitudes seem to have higher racial and gender intolerance as well as higher anxiety and fear of other racial groups and less empathy for them. Denial of this form of systemic racism may contribute to a 'blame the victim' mentality, which helps to maintain the status quo (Kestner 2009:19, 20).

In our study, racial prejudice was operationalised through an adaptation of the MRS. Students had to respond to the different items on the scale, and it was refined and validated through a factor analysis.

\section{Just-world beliefs}

This study also investigated the students' just-world beliefs. Before the higher education institution merger in 2004, what is now part of the NWU in the form of its Potchefstroom Campus was an independent university led by a conservative Protestant elite (Kamsteeg 2008:444; Pretorius 2017:20). This Protestant world view implies a work ethic that contributes to a just-world belief as demonstrated by Furnham and Rajaminickam (1992:410). As today's Afrikaans-speaking students traditionally stem from this Protestant background, it is expected that there would be adherence to a just-world belief. Therefore, our research attempted to determine the extent to which a just-world belief contributes to colour-blind attitudes. The answer could assist in the design of a focused transformation intervention.

Lerner (1977) initiated the concept of just-world beliefs, which claims that people believe in a world where, in general, if you are a good individual, good things will happen to you, and if you are a bad individual, bad things will happen to you. People have a strong need to believe that the world is a fair and just place where people obtain what they deserve, and nothing less, in order for them to determine their own fate (Kestner 2009:1). Beliefs in a just world can cause 
privileged people to hold disadvantaged people accountable for their own problems and play down existing needs; in this way, personal privileges can continue to be justified (Kestner 2009:1). Empirical research has found that just-world beliefs forecast prejudiced attitudes towards a variety of disadvantaged groups, including the underprivileged, people with acquired immunodeficiency syndrome, the elderly, the unemployed and refugees (Kestner 2009:11). Therefore, regardless of many healthy meanings related to beliefs about the world as just, these beliefs may also direct a person to deny inequality and engage in victim derogation (Kestner 2009:3-4). This just-world phenomenon seems to overlap with colour-blind attitudes, as these also uphold prejudiced attitudes and underemphasise social inequality (see Kestner 2009:6). Studies have found that students with higher rates of colour-blind racial attitudes also held views of the world as a just place (Neville et al. 2000; Tynes \& Markoe 2010:2-3)

In our research, the questionnaire items on just-world beliefs stemmed from Kestner's Just World Scale (Kestner 2009:86-87). Students answered different relevant items on the scale, and factor analysis was then applied to the results.

\section{Social dominance orientation}

Finally, our study also focused on the students' social dominance orientation. A dominant culture of whiteness contributes to inequality in higher education institutions (Kamsteeg 2008:447). This seems to exist at the campus, as it has been reported that the Afrikaans culture on the campus was experienced by students from other cultures as a hostile and foreign environment that made them feel unwelcome (Pretorius 2017:189-190). This kind of dominant cultural position contributes to a social dominance orientation. We, therefore, deemed it necessary to ascertain whether such a social dominance orientation reinforces colour-blind attitudes.

According to Kestner (2009:24), social dominance orientation is defined as the extent to which people desire and support the stance that their own group is superior to groups that do not fit in with theirs. Social dominance orientation operates as a motivating aspect that justifies social inequalities. It denigrates individuals from the out-group, and members of marginal groups in particular (Kestner 2009:24). A study conducted by Kestner (2009) on colour-blind attitudes and social dominance orientation indicated a positive relationship between the two. Worthington et al. (2008) also found a moderate positive relationship between the scores of colourblind attitudes and social dominance orientation. Many decades ago, Blumer (1958:4) argued that, in racialised contexts, the dominant group is not mainly concerned with the subordinate group as much as it is concerned with their own position in society, because this is a way for them to understand intergroup relations. From this perspective, the dominant group is not ignorant of race but rather seeks out its own group interests by dismissing race as a basis of inequality (Vargas 2014:2285).
Our study operationalised the social domination orientation by adapting questions from Kestner's Social Dominance Orientation Scale (Kestner 2009:91-92). The students reacted to items on the scale, and it was refined through factor analysis.

The discussion of the literature in this section has suggested the identification of race, gender, racial prejudice, just-world beliefs and social dominance orientation as social factors that can possibly contribute to colour-blind attitudes on the Potchefstroom Campus. Deemed relevant for the research site, these social factors were selected for investigation in the present study.

\section{Research methodology and design Research approach}

The theoretical foundation of quantitative methodology is directed by a realist and objectivist ontology and by an empiricist epistemology (Sarantakos 2013:31). Quantitative approaches generally take on a nomothetic methodology that aims at recognising and formulating generally applicable statements (Gelo, Braakmann \& Benetka 2008:271). Thus, quantitative approaches are deductive and theory driven (Antwi \& Hamza 2015:220). According to Muijs (2004:1), quantitative research 'explains phenomena by collecting numerical data that are analysed using mathematically based methods (in particular statistics)'. A quantitative research approach is suitable for this study, because it can statistically determine the relationship between race, gender, racial prejudice, just-world beliefs and social dominance orientation on the one hand and colour-blind attitudes on the other hand.

A research design can be described as a plan of how the researcher will conduct the research (Babbie \& Mouton 2001:74). For the purpose of this study, we employed a crosssectional survey design. According to Bryman (2012), this:

[E]ntails the collection of data on more than one case and at a single point in time in order to collect a body of quantitative or quantifiable data in connection with two or more variables, which are then examined to detect patterns of association. (p. 58)

\section{Population and sample}

In this study, the population comprised undergraduate students of the NWU Potchefstroom Campus. On 06 June 2017, the population comprised 17072 students, of whom $57 \%$ were males and $43 \%$ females; $71 \%$ were white, $22 \%$ black and $7 \%$ from other races. Sampling can be defined as the procedure by which the researcher identifies and selects people who are representatives of the population to use in their study (Babbie \& Mouton 2001:164). In the present study, the non-probability quota sampling method was used. According to Sarantakos (2013:172), it entails dividing the target population into a number of homogeneous, nonoverlapping subgroups and drawing a sample from each subgroup. In our study, the subgroups were determined by students' sex, faculty and race, and a sample of 300 students was selected, so that the subgroups were proportionally the same as in the population. 


\section{Data collection strategy}

A questionnaire was constructed to measure the chosen variables, and it was then tested in a pilot study. The combination questions for colour-blind attitudes were based on the CoBRAS and the questions for racial prejudice were adapted from the MRS. The questions for the just-world beliefs stemmed from Kestner's Just World Scale (Kestner 2009:86-87), and the social dominance orientation questions were constructed from Kestner's Social Dominance Orientation Scale (Kestner 2009:91-92). To evaluate the construct validity of the scales, a panel of sociologists from the Potchefstroom Campus examined them. They did not find the scales fully applicable to the research setting. They, therefore, selected those items in the scales that were most fitting and added others that were obvious for the setting.

Interviews were used to administer the questionnaires. These interviews for the survey were conducted by sociology honours students on the campus. Each conducted 30 structured interviews. Appointments were made with students and interviews conducted at a place that suited the respondents. A structured interview schedule was used that had been pre-tested to ensure that the items were understandable, stable, reliable and valid when answered by the undergraduate students. After the collection of the data an additional effort was made to ensure the internal reliability of the scales. For this purpose, principal axis factoring was applied. First, the Kaiser-Meyer-Olkin (KMO) test and Bartlett's test table were used to test whether the factor analysis was acceptable based on the correlations. This was followed by applying an anti-image correlation that indicated the measures of sampling adequacy (MSA). This presented the items' correlation. Only items with an MSA value of 0.6 and above were retained. Cronbach's alpha, as a statistic measuring reliability, was then used to establish the extent to which the items for the factor were collectively correlated. Special effort was thereby made to ensure the validity and reliability of the measurements.

\section{Analysis and reporting}

As this was a quantitative study, the data from the interviews were statistically analysed with SPSS. Besides the factor analysis, we used descriptive statistics, correlations and $t$-tests to analyse the data. Correlation coefficient $r$ was used as the effect size to determine the strength of relationship between the selected variables, where $r=0.10$ was considered a small effect, $r=0.30$ a medium effect and $r=0.5$ as a large effect (Field 2005:32).

\section{Limitations}

The study focused on undergraduate students studying on only one of the three NWU campuses. The reason was that this campus was most assessable for the researchers and its white people, apartheid-dominant past. This means that the results can be generalised only to undergraduate students at the Potchefstroom Campus. Furthermore, the sample was small relative to the campus population; therefore, additional care is needed when generalising from the findings. However, the homogeneity of the student population presented the potential for considered generalising.

\section{Ethical considerations}

This research study was formally approved by the Ethics Committee of the Faculty of Arts of the NWU (Ethics number: NWU-00067-14-S7). The researchers adhered to the ethical requirements. Each respondent signed an informed consent form permitting the researchers to include them in the research. The informed consent form clarified the purpose of the study as well as the nature of the research and ensured the privacy, anonymity and confidentiality of the respondents. No student was forced to participate in the study, and they were informed that they could withdraw from the study at any time. Appointments were scheduled by the researchers at times when the sampled respondents were free, and faceto-face interviews took place in agreed-upon venues.

\section{Empirical results Colour-blind attitudes as the dependent variable}

An exploratory factor analysis was conducted on the 12 items related to colour-blind attitudes measured with a Likert-type scale. The response categories were $1=$ strongly disagree; 2 = disagree; 3 = neutral; 4 = fairly strongly agree and $5=$ very strongly agree. Principal axis factoring was used, whereby the dimensionality of the colour-blind attitudes instrument was determined. The KMO test measured 0.86 and indicated that the sample size was adequate for factor analysis. The $p$-value of Bartlett's test of sphericity returned a value smaller than 0.05 , suggesting that the correlation between statements was sufficient for factor analysis (Field 2005:652). A factor with eight items related to colour-blind attitudes was extracted. The factor loadings of the colour-blind attitudes factor ranged from 0.459 to 0.856 . The colour-blind attitudes factor showed a Cronbach's alpha coefficient of 0.87 , which indicates that the result is reliable. The Kolmogoroy-Smirnov and Shapiro-Wilk tests indicated that the distribution was negatively skewed. The mean for the factor was 3.56, meaning that the respondents held a neutral-to-agree attitude on the colour-blind attitude scale.

\section{Effect of race on colour-blind attitudes}

Self-identified black students obtained a colour-blind racism mean of 2.6085, whereas white students obtained a mean of 3.9065. This seems to indicate that the black students were less colour-blind than the white students. To ascertain this, Levene's test and $t$-test were used by means of SPSS analysis. The Levene's test was applied to establish whether the variances amongst the black students and the white students were equal. The significance of Levene's test for equality of variance was 0.014 , meaning that the $p$-value was smaller than 0.05 and, as a result, equal variances were not assumed. As a result of this, the $t$-test $p$-value used was associated with equal variances not assumed. This $p$-value must be $<0.05$ to reject the null hypothesis, which posits that groups have equal means. The $p$-value for the factor colour-blind attitudes 
measured $0.000(p<0.05)$. The results of the $t$-test, therefore, indicated statistically significant differences between the means of white students and black students on their colourblind attitudes. This indicated that the colour-blind attitudes' mean of self-identified black students was statistically significantly lower than the colour-blind mean of selfidentified white students. The null hypothesis indicated that there was no relationship between undergraduate students' race; and their colour-blind attitude was, therefore, rejected.

\section{Effect of gender on colour-blind attitudes}

Male students measured a colour-blind attitudes' mean of 3.5830, whilst female students obtained a mean of 3.5723 . This seems to indicate no significant difference between levels of male and female students' colour-blind attitudes. To ascertain whether this was indeed so, the Levene's test and $t$-test were used. The Levene's test was applied to establish whether the variances amongst the male students and the female students were equal. The significance of Levene's test for equality of variance was 0.805 , meaning that this $p$-value is greater than 0.05 and, as a result, equal variance could be assumed. In the case of the present study, the $t$-test $p$-value was $0.917>0.05$, indicating an insignificant statistical difference between the means of male and female undergraduate students with regard to their colour-blind racial attitudes. This confirmed that no relationship existed between undergraduate students' gender and their colourblind racial attitudes, which indicated no significant difference between male and female students on the measurement of the colour-blind attitudes' scale.

\section{Racial prejudice}

A factor analysis was conducted on the six Likert-type scale items to measure racial prejudice. Principal axis factoring was used. The sample size was adequate for factor analysis because the KMO measured 0.72. The correlation between statements was sufficient for factor analysis because the $p$-value of Bartlett's test of sphericity returned a value smaller than 0.05 . One factor was extracted as related to racial prejudice. The factor loading ranged from 0.626 to 0.810 . The Cronbach's alpha coefficient of the factor on racial prejudice was 0.78 , indicating high reliability and internal consistency. The mean score of the factor was 3.02, indicating a tendency amongst respondents towards neutrality on items measuring racial prejudice attitudes. The distribution was slightly positively skew.

\section{Racial prejudice and colour-blind attitudes}

A correlation test, the Spearman rank correlation coefficient, was used to test whether the two factors, racial prejudice and colour-blind attitudes, were correlated. The assumption was that if normality is not met, as in this case, the Spearman rank correlation coefficient should be used (Eiselen \& Uys 2016:100). The $p$-value of significance was 0.000 , which is smaller than 0.05, and this indicated that the correlation between racial prejudice and colour-blind attitudes was significant. There was a medium positive correlation (0.365) between the two variables. This means that students who were racially prejudiced tended towards a higher colourblind attitude score.

\section{Just-world beliefs}

A factor analysis was conducted on the six Likert-type scale items to measure the underlying dimensions of perceptions of just-world beliefs. Principal component analysis was used. The KMO measured 0.68, which indicated that the sample size was adequate for factor analysis. The $p$-value of Bartlett's test of sphericity returned a value of smaller than 0.05 , suggesting that the correlation between statements was sufficient for factor analysis (see Field 2005). A factor with five items was extracted related to just-world beliefs. The factor loadings ranged from 0.534 to 0.754 . The Cronbach's alpha coefficient of the factor on just-world beliefs was 0.73 , indicating high reliability and internal consistency. The mean score was 3.24 indicating a tendency towards neutral to slight agreement amongst the respondents. The distribution was non-normal.

\section{Just-world beliefs and colour-blind attitudes}

A correlation test, the Spearman rank correlation coefficient, was used to test whether the two factors, just-world beliefs and colour-blind attitudes, were correlated. The assumption is that if normality is not met, as in this case, the Spearman rank correlation coefficient should be used (Eiselen \& Uys 2016:100). The $p$-value of significance was 0.001 , which is smaller than 0.05 , indicating that the correlation between just-world beliefs and colour-blind attitudes was significant. There was a small positive correlation (0.191) between the two variables. This means that students with just-world beliefs might have had a slight tendency towards colour-blind attitudes.

\section{Social dominance orientation}

A factor analysis was conducted on the six Likert-type scale items to measure the underlying dimensions of social dominance-orientation attitudes. Principal component analysis was used. The KMO measured 0.76 , indicating that the sample size was adequate for factor analysis. The $p$-value of Bartlett's test of sphericity returned a value of less than 0.05 . This suggests that the correlation between statements was sufficient for factor analysis. A factor with six items was extracted as related to social dominance orientation. The factor loadings ranged from 0.377 to 0.643 . The Cronbach's alpha coefficient of the factor on social dominance orientation was 0.73. The mean score of the factor was 3.67, indicating a tendency amongst respondents to agree to the items on the social dominance orientation scale. The factor had a nonnormal distribution.

\section{Social dominance orientation and colour-blind attitudes}

A correlation test, the Spearman rank correlation coefficient, was used to test whether the two factors, social dominance orientation and colour-blind attitudes, were correlated. 
The assumption is that if normality is not met, as in this case, the Spearman rank correlation coefficient should be used (Eiselen \& Uys 2016:100). The $p$-value of significance calculated at 0.001 , which is smaller than 0.05 , indicates that the correlation between social dominance orientation and colour-blind attitudes was significant. There was a small negative relationship $(-0.191)$ between the two variables. This means that students with a factor-based social dominance orientation measured to a slight extent less on their factor-based colour-blind attitudes.

\section{Discussion}

The purpose of this study was to explore the extent of colourblind attitudes amongst undergraduate students at the NWU on its Potchefstroom Campus and the effect of selected relevant social factors (such as race, gender, racial prejudice, just-world beliefs and social dominance orientation) on their colour-blind racial attitudes. Our results indicated that colour-blind attitudes were not strong amongst the students; the deviation of the mean score from the neutral position on the scale towards agreement with colour-blind attitudes was limited.

The findings from our research that racial identification relates to colour-blind attitudes were consistent with several studies in the United States of America. Neville et al. (2000:63), for instance, reported that black people would tend to report a lesser extent of colour-blind attitudes than white people because they are more sensitive to racial prejudice. Their findings were supported later by Cheng (2015) who reported that white and black people had dissimilar levels in adopting a colour-blind standpoint, with black people less colour-blind than white people. He argues that colour-blind racial ideology upholds the dominant white culture through a systemic process of marginalisation of people of colour (Cheng 2015:3). Bobo and Fox (2003:323) had argued, earlier, that white people adopt a colour-blind standpoint because it may assist in guarding them against recognising racial inequalities in society, thus assisting in a lessening of any conflict or dissonance that may come into play. The denial of such inequalities can promote inaction which, in turn, helps to preserve the privileges that many white people, especially white elites, continue to receive from the current system (Neville et al. 2000:69). Our South African study did not aim at determining these or similar underlying motives for colourblind attitudes amongst white undergraduate students on the Potchefstroom Campus of the NWU. In our case, the white students may have felt that identifying racial inequalities in society could bring about conflict between the races and, to avoid this, they might prefer not to talk about or acknowledge the existing racism. This suggestion calls for further research.

Although Neville et al. (2000:68) reported lower colour-blind racial attitudes amongst women than amongst men, the present study did not find a similar difference between genders in our sample. Kestner (2009:22) argued that women may be less likely to hold racist attitudes, given their experience of gender discrimination, and that continuing gender discrimination may make women become more aware of gender and other societal oppressions in view of their personal experiences as they progress through college (2009:22). One reason why our results did not align with the literature could be that, nearly a decade after Kestner's study in the United States of America, female students in South Africa had grown up in an explicitly more democratic world than before, and that, therefore, young female undergraduate students on the NWU Potchefstroom Campus had not experienced the same discriminatory practices as earlier generations had experienced. Such issues offer opportunities for further investigation.

Worth noting was the statistically significant relationship found in our study between undergraduate students' measurements on a racial prejudice scale and on a colourblind attitude scale. In this correlation, students who scored higher on the racially prejudiced scale tended to have a higher score on the colour-blind attitude scale. This supports previous findings elsewhere. McConahay (1986) had argued that there is a conceptual and empirical linkage between colour-blind attitudes and racial prejudice, as demonstrated by research indicating a significant positive relationship between CoBRAS and MRS. A decade later, Carr (1997) reported a positive correlation between racist attitudes such as racial prejudice and colour-blind attitudes, followed by Neville et al. (2000:68) who proposed that the greater one's racial prejudice against other groups, the more likely one is to maintain colour-blind attitudes. Bonilla-Silva (2003) concurred, claiming that people who hold prejudiced views tend to endorse a colour-blind ideology. In a study conducted by Richeson and Nussbaum (2003) on the impact of multiculturalism versus colour-blindness on racial bias, greater levels of racial prejudice were found in people with a colour-blind perspective than in those with a multicultural perspective. The present South African study confirms the positive relationship between racial prejudice and colourblind racial attitudes, which indicates that Potchefstroom Campus students may have colour-blind attitudes - thereby denying racial dynamics - whilst they continue to entertain racial prejudices. The correlation in our sample indicates only a medium relationship between the two factors, however, not a strong one. It nonetheless demonstrates that colour-blind attitudes are not innocent but can accommodate stereotypical views of people belonging to other race groups.

We found a small positive correlation in our research regarding the relationship between undergraduate students' just-world beliefs and colour-blind racial attitudes. This finding is consistent with an argument made by Neville et al. (2000:63) that the belief in a just world correlates with colour-blind attitudes, and that there is a conceptual link between a belief in a just-world and colour-blind attitudes; both concepts include a level of unawareness or ignorance about negative forces in society, such as racism, and both foster a 'blame the victim' perspective that, whatever the circumstances, holds people accountable for their misfortunes. Building on Neville et al. (2000), Kestner (2009:6) asserts that people who believe in a just world may also hold colour-blind racial attitudes, resulting 
in failure to recognise the inequalities that persist in society. Our results led us to conclude that a limited tendency may be found amongst undergraduate students on the Potchefstroom Campus to think that people deserve what they obtain and also to maintain colour-blind attitudes. In addition, our results suggest that efforts to address colour-blind attitudes should also give attention to just-world beliefs, as these can contribute - in however small a way - to colour-blind attitudes.

The relationship that we found between undergraduate students' social dominance orientation and colour-blind attitudes showed a small negative correlation, as indicated. This deviates from Kestner (2009) who indeed found a relationship between social dominance orientation and colour-blind racial attitudes. Neville et al. (2005), Worthington et al. (2008) and Cheng (2015) also found a relationship between social dominance orientation and colour-blind racial attitudes. Our results from the Potchefstroom Campus undergraduate student sample are different; lower levels of correlation between social dominance orientations and higher colour-blind attitudes may, perhaps, reflect the emphasis in South Africa's new constitution on individual rights over group rights, resulting in lower levels of social dominance orientation and less emphasis on group domination in their attitudes. The lesser the level on which group interests are valued, the lesser the level at which students may find it necessary to pay attention to racial issues, which would contribute to colour-blind attitudes.

In summary, our study represents a contribution to the study of colour-blind attitudes in South Africa that is limited in size and scope, as it focuses on undergraduate students at the NWU Potchefstroom Campus. Its value, however, is that it gives a unique snapshot of the existence of a different form of racism after 1994 (i.e. from legislated racism to colour-blind attitudes). In view of this, we underscore some of the key contributions that it makes in shedding light on ways to measure and assess colourblind attitudes that can undermine transformation:

- This study did not find a high level of colour-blind attitudes amongst the students in the sample, which may relate to the fact that they are part of the free-born generation. It would, therefore, be interesting to compare these findings with groups of older people. However, the fact that colour-blind attitudes exist amongst these students demonstrates the need for the institution to plan to provide more space for students to talk openly about race and issues concerning race, to ensure that they do not simply lapse into ignoring them. This recommendation corresponds to the emphasis in the NWU Transformation Charter (North-West University 2012:2) on the importance of dialogue, communication and ongoing and robust engagement.

- The differences between black students and white students may relate to a deeper divide around interpretations about what South African society is and ought to be. Further study of the racial interpretations of relevant groupings can help universities, and also South African society more broadly, to review and improve the interventions needed to close the gaps between these groupings. Our study also demonstrates the importance of the NWU Transformation Charter (North-West University 2012) argument for increased access and unity in student experience and equitable resource allocation.

- Of interest, and in contrast to the literature, no difference in colour-blind racist attitudes could be found between male and female students in our study. This result emphasises the potential value of further gender studies to explore how women understand and interpret their experiences of race and their role in South African society. The absence of a gender equality agenda is salient in the NWU Transformation Charter (North-West University 2012) and the histories of transformation at the NWU (Pretorius 2017; Prinsloo 2016) and further demonstrates the necessity for research in this area, on this and other campuses.

- Racial prejudice, just-world beliefs and social dominance orientation were shown to be interesting variables for the study of colour-blind attitudes in a racially complex society. The present study established a medium relationship between racial prejudice and colour-blind attitudes, and a limited relationship between just-world beliefs and social dominance orientation and colourblind attitudes. In contrast to the literature, we found the significant relationship between social domination orientation and colour-blind attitudes to be slightly negative. This suggests opportunities for qualitative research that would explore these variables further and reveal the dynamics related to the interpretations that arise around them. The NWU context confirms that transformation is inextricably connected to issues of justice, culture, communal well-being, equity and increased unity. All these are emphasised in the NWU Transformation Charter (North-West University 2012) and can pave the way for further studies and greater understanding.

\section{Conclusion}

This research shed light on the extent of colour-blind attitudes amongst undergraduate students of NWU's Potchefstroom Campus and their relationship to the social factors of race, gender, racial prejudice, just-world beliefs and social dominance orientation. Our results indicate that some degree of colour-blind attitudes exists amongst the students. Furthermore, the study clearly reveals a relationship between race and colour-blind attitudes, a medium relationship between racial prejudice and colourblind attitudes and a small relationship between just-world beliefs, social dominance orientation and colour-blind attitudes. However, in contrast to the literature, we found no relationship between undergraduate students' gender and colour-blind attitudes. 
This is the first research study on colour-blind attitudes on this campus and the findings give a unique insight into students' attitudes that relate specifically to the NWU transformation agenda. We found evidence that colour-blind attitudes have some foothold amongst undergraduate students on the university's Potchefstroom Campus, which can hinder its transformation processes. The study contributes more broadly to an understanding of social factors that affect these attitudes, which potentially have relevance not only for the university in this study but more widely in South Africa's higher education institutions and in other professional contexts. This small-scale study, we believe, opens the door to further research in the field of colour-blind attitudes in the country, as it continues to grapple with the challenges of transformation.

\section{Acknowledgements}

We would like to acknowledge the students of the 2017 Sociology honours class at the North-West University, Potchefstroom campus who all acted as interviewers in the survey on which this study is based.

\section{Competing interests}

The authors declare that they have no financial or other relationships that may have inappropriately influenced them in writing this article.

\section{Authors' contributions}

J.-L.A. conducted the literature review as well as the empirical research and presented it in honour of the mini-dissertation titled 'Colour-blind racial attitudes of students on the NorthWest University, Potchefstroom Campus'. J.Z. acted as the supervisor of the research project, assisted with the literature review, guided the statistical analysis and wrote the article.

\section{Funding information}

This research received no specific grant from any funding agency in the public, commercial, or not-for-profit sectors.

\section{Data availability}

Original data were collected and analysed in this study. The data have no linkage to the specific interviewees. Confidentiality is, therefore, protected by the data. In the case of a reasonable request, the data for the variables discussed in this article can be made available.

\section{Disclaimer}

The views, opinions, findings and recommendations expressed in this article are those of the authors and do not reflect the policy or position of affiliated agencies of the authors.

\section{References}

Amoateng, A.Y. \& Kalule-Sabiti, I., 2014, 'Social context factors and attitudes toward interracial relationships on a South African University Campus', African Population Studies. Supplement on Population Issues in South Africa 28(1), 623-635. https:// doi.org/10.11564/28-0-520
Antwi, S.K. \& Hamza, K., 2015, 'Qualitative and quantitative research paradigms in business research: A philosophical reflection', European Journal of Business and Management 7(3), 217-225.

Babbie, E. \& Mouton, J., 2001, The practice of social research. South Africa, Oxford University Press, Cape Town.

Blumer, H., 1958, 'Race prejudice as a sense of group position', The Pacific Sociological Review 1(1), 3-7. https://doi.org/10.2307/1388607

Bonilla-Silva, E., 2003, 'Racial attitudes or racial ideology? An alternative paradigm for examining actors' racial views', Journal of Political Ideologies 8(1), 63-82. https:// doi.org/10.1080/13569310306082

Bobo, L.D. \& Fox, C., 2003, 'Race, racism, and discrimination: Bridging problems, methods, and theory in social psychological research', Social Psychology Quarterly 66(4), 319-332. https://doi.org/10.2307/1519832

Bryman, A., 2012, Social research methods, 4th edn., Oxford University Press, New York, NY.

Burke, M., 2019, Colorblind racism, Polity Press, Cambridge.

Carr, L.G., 1997, 'Color-blind' racism, Sage, London.

Cheng, S.J., 2015, 'Psychometric examination of the color-blind racial attitudes scale for use among Asian Americans', PhD thesis, University of Illinois, Chicago, IL.

Coates, R.D., 2011, Covert racism: Theories, institutions, and experiences, Brill, Leiden, Boston, MA.

Dovidio, J.F., Pearson, A.R. \& Geartner, S.L., 2009, 'The nature of contemporary prejudice: Insights from aversive racism', Social and Personally Psychology Compass 3, 1-25.

Eiselen, R. \& Uys, T., 2016, Analysing survey data using SPSS version 22, 5th edn., University of Johannesburg, Johannesburg.

Field, A., 2005, Discovering statistics using SPSS, Sage, London.

Furnham, A. \& Rajamanickam, R., 1992, 'The protestant work ethic and just world beliefs in Great Britain and India', International Journal of Psychology 27(6), 401-416. https://doi.org/10.1080/00207599208246905

Gelo, O., Braakmann, D. \& Benetka, G., 2008, 'Quantitative and qualitative research: Beyond the debate', Integrative Psychological Behavioural Science 42(3), 266-290. https://doi.org/10.1007/s12124-008-9078-3

Greenstein, R., 2015, 'Race', in P. Stewart \& J. Zaaiman (eds.), Sociology: A South African introduction, pp. 174-195, Juta, Cape Town.

Kamsteeg, F., 2008, 'In search of a merged identity: The case of multi-campus NorthWest University, South Africa', Journal for Transdisciplinary Research in Southern Africa 4(2), 431-451. https://doi.org/10.4102/td.v4i2.162

Kamsteeg, F., 2011, 'Transformation as social drama: Stories about merging at North-West University, South Africa', Anthropology Southern Africa 34(1\&2), 51-61, http://dx.doi.org/10.1080/23323256.2011.11500008

Kestner, J.M., 2009, 'Relating colour-blind racial attitudes, social dominance orientation and just world beliefs', PhD thesis, Loyola University, Chicago, IL.

Lerner, M.J., 1977, 'The justice motive: Some hypotheses as to its origins and forms', Journal of Personality 45(1), 1-32. https://doi.org/10.1111/j.1467-6494.1977. tb00591.x

Mazzocco, P.J., 2015, 'Talking productively about race in the colour-blind era', viewed 21 May 2017, from http://kirwaninstitute.osu.edu/docs/ki-racetalk-0115-05.pdf

McConahay, J.B., 1986, 'Modern racism, ambivalence, and the Modern Racism Scale', in J.F. Dovidio \& S.L. Gaertner (eds.), Prejudice, discrimination, and racism, pp. 91-125, Academic Press, Washington, DC.

McDonald, C.P., 2016, 'The relationships among multiracial identity, colour-blind racial ideology, and discrimination in multiracial individuals: Implications for professional counselling and counsellor education', PhD thesis, Georgia State University, Atlanta, GA.

Muijs, D., 2004, Doing quantitative research in education, Sage, London.

Neville, H., Coleman, N., Falconer, J.W. \& Holmes, D., 2005, 'Color-blind racial ideology and psychological false consciousness among African Americans', Journal of Black Psychology 31(1), 27-45. https://doi.org/10.1177/0095798404268287

Neville, H.A., Lilly, R.L., Duran, G., Lee, R.M. \& Browne, L., 2000, 'Construction and initial validation of the Colour-Blind Racial Attitudes Scale (CoBRAS)', Journal of Counseling Psychology 47(1), 59-70. https://doi.org/10.1037/00220167.47.1.59

Neville, H.A., Poteat, V.P., Lewis, J.A. \& Spanierman, L.B., 2014, 'Changes in White college students' color-blind racial ideology over 4 years: Do diversity experiences make a difference?', Journal of Counseling Psychology 61(2), 179-190. https://doi. org/10.1037/a0035168

North-West University, 2012, 'NWU Transformation Charter, 2012', viewed 28 January 2020, from http://www.nwu.ac.za/sites/www.nwu.ac.za/files/files/i-governancemanagement/policy/2Pr-2.7_transformation-charter.pdf

Pearson, A.R., Dovidio, J.F. \& Geartner, S.L., 2009, 'The nature of contemporary prejudice: Insights from aversive racism', Social and Personally Psychology Compass 3(3), 1-25. https://doi.org/10.1111/j.1751-9004.2009.00183.x

Pretorius, C., 2017, Forging unity: The story of the North-West University's first 10 years, viewed 28 January 2020, from https://repository.nwu.ac.za/ handle $/ 10394 / 26089$ ?show=full 
Prinsloo, P.J.J., 2016, North-West University (NWU): A merger and incorporation story, 2004-2014, viewed 28 January 2020, from https://repository.nwu.ac.za/ handle/10394/26017

Puttick, K., 2011, 'First year students' narratives of race and racism in post-apartheid South Africa', MA dissertation, University of Witwatersrand Johannesburg.

Rabe, M., 2015, 'Gender', in P. Stewart \& J. Zaaiman (eds.), Sociology: A South African introduction, pp. 151-169, Juta, Cape Town.

Richeson, J.A. \& Nussbaum, R.J., 2003, 'The impact of multiculturalism versus colorblindness on racial bias', Journal of Experimental Social Psychology 40(3) 417-423. https://doi.org/10.1016/j.jesp.2003.09.002

Sarantakos, S., 2013, Social research, 4th edn., Palgrave Macmillan, New York, NY.
Tynes, B.M. \& Markoe, S.L., 2010, 'The role of color-blind racial attitudes in reactions to racial discrimination on social network sites', Journal of Diversity in Higher Education 3(1), 1-13. https://doi.org/10.1037/a0018683

Vargas, N., 2014, 'Off white: Colour-blind ideology at the margins of whiteness', Ethnic and Racial Studies 37(13), 2281-2302. https://doi.org/10.1080/01419870.2013.8 21147

Winant, H., 1998, 'Racism today: Continuity and change in the post-civil rights era', Ethnic and Racial Studies 21(4), 755-766. https://doi. rights erg/10.1080/014198798329856

Worthington, R.L., Navarro, R.L., Loewy, M. \& Hart, J., 2008, 'Colour-blind racial attitudes, social dominance orientation, racial-ethnic group membership and college students' perceptions of campus climate', Journal of Diversity in Higher Education 1(1), 8-19. https://doi.org/10.1037/1938-8926.1.1.8 


\section{Appendix 1: Questionnaire}

\section{Section 1: Demographic and profile information}

1. Are you an undergraduate student? Only interview undergraduate students.

\begin{tabular}{|c|c|c|c|c|}
\hline Yes & 1 & No & 2 & If 'No', thank and close interview \\
\hline
\end{tabular}

2. In what faculty are you currently registered? Single response. Do not prompt.

\begin{tabular}{|l|l|}
\hline Faculty of study & 1 \\
\hline Arts & 2 \\
\hline Natural sciences & 3 \\
\hline Theology & 4 \\
\hline Education sciences & 5 \\
\hline Economic and management sciences & 6 \\
\hline Law & 7 \\
\hline Engineering & 8 \\
\hline Health Sciences & \\
\hline
\end{tabular}

3. What is your current year of study? Single response only.

\begin{tabular}{|c|c|c|c|}
\hline First Year & 1 & Senior & 2 \\
\hline
\end{tabular}

4. Which sex/gender do you identify yourself with? Single response. Do not prompt.

\begin{tabular}{|l|l|l|l|l|l|}
\hline Male & 1 & Female & 2 & Other & 3 \\
\hline
\end{tabular}

5. Which race do you classify yourself as? Single response. Do not prompt.

\begin{tabular}{|l|l|l|l|l|l|l|l|l|l|}
\hline Black & 1 & White & 2 & Asian & 3 & Mixed race & 4 & Other & 5 \\
\hline
\end{tabular}

\section{Section 13: Race relations questions}

41. I will read you a number of statements. Please indicate the extent to which you agree or disagree with the following statements relating to colour-blind racial attitudes. Using the 5-point on the card, simply read out the number. Hand respondent show card. One response per line.

\begin{tabular}{|c|c|c|c|c|c|c|}
\hline \multicolumn{2}{|c|}{ Statements } & \multirow{2}{*}{$\begin{array}{c}\text { Strongly } \\
\text { disagree }\end{array}$} & \multirow{2}{*}{$\begin{array}{c}\text { Disagree } \\
2\end{array}$} & \multirow{2}{*}{\begin{tabular}{|c|}
$\begin{array}{c}\text { Somewhat } \\
\text { agree }\end{array}$ \\
3
\end{tabular}} & \multirow{2}{*}{$\begin{array}{c}\text { Agree } \\
4\end{array}$} & \multirow{2}{*}{\begin{tabular}{|c|}
$\begin{array}{c}\text { Strongly } \\
\text { agree }\end{array}$ \\
5
\end{tabular}} \\
\hline 41.1 & $\begin{array}{l}\text { Everyone who works hard, no matter what race they are, has an equal } \\
\text { chance to become rich. }\end{array}$ & & & & & \\
\hline 41.2 & $\begin{array}{l}\text { Race plays a role in the quality of services that students receive on the } \\
\text { Potchefstroom Campus. }{ }^{\circledR}\end{array}$ & 1 & 2 & 3 & 4 & 5 \\
\hline 41.3 & $\begin{array}{l}\text { It is important that people begin to think of themselves as only South } \\
\text { African and not white, black, mixed race, Indian, etc. }\end{array}$ & 1 & 2 & 3 & 4 & 5 \\
\hline 41.4 & $\begin{array}{l}\text { As a result of apartheid racial discrimination, programmes such as } \\
\text { affirmative action (favouring black people to redress previous } \\
\text { disadvantages) are necessary to help create equality. }{ }^{\circledR}\end{array}$ & 1 & 2 & 3 & 4 & 5 \\
\hline 41.5 & Racism is a problem on the Potchefstroom Campus. ${ }^{\circledR}$ & 1 & 2 & 3 & 4 & 5 \\
\hline 41.6 & Race determines who will be successful and who will not be. ${ }^{\circledR}$ & 1 & 2 & 3 & 4 & 5 \\
\hline 41.7 & Racism is not an important problem in South Africa today. & 1 & 2 & 3 & 4 & 5 \\
\hline 41.8 & $\begin{array}{l}\text { On the Potchefstroom Campus, black students do not have the same } \\
\text { opportunities as students from other race groups. }\end{array}$ & 1 & 2 & 3 & 4 & 5 \\
\hline 41.9 & Talking about racial issues causes unnecessary tension. & 1 & 2 & 3 & 4 & 5 \\
\hline 41.10 & It is important for students to discuss racism on the Potchefstroom Campus. ${ }^{\circledR}$ & 1 & 2 & 3 & 4 & 5 \\
\hline 41.11 & $\begin{array}{l}\text { White students on the Potchefstroom Campus have certain advantages } \\
\text { because of the colour of their skin. }{ }^{\circledR}\end{array}$ & 1 & 2 & 3 & 4 & 5 \\
\hline 41.12 & $\begin{array}{l}\text { White students are more to blame for racial discrimination than students } \\
\text { from other racial groups. }\end{array}$ & 1 & 2 & 3 & 4 & 5 \\
\hline
\end{tabular}


42. I will read you a number of statements. Please indicate the extent to which you agree or disagree with the following statements relating to racial prejudice. Using the 5-point on the card, simply read out the number. Hand respondent show card. One response per line.

\begin{tabular}{|c|c|c|c|c|c|c|}
\hline \multicolumn{2}{|c|}{ Statements } & \multirow{2}{*}{$\begin{array}{c}\begin{array}{c}\text { Strongly } \\
\text { disagree }\end{array} \\
1\end{array}$} & \multirow{2}{*}{$\begin{array}{c}\text { Disagree } \\
2\end{array}$} & \multirow{2}{*}{$\begin{array}{c}\begin{array}{c}\text { Somewhat } \\
\text { agree }\end{array} \\
3 \\
\end{array}$} & \multirow{2}{*}{$\begin{array}{c}\text { Agree } \\
4\end{array}$} & \multirow{2}{*}{$\begin{array}{c}\begin{array}{c}\text { Strongly } \\
\text { agree }\end{array} \\
5\end{array}$} \\
\hline 42.1 & White people are emphasising equal rights too much. & & & & & \\
\hline 42.2 & $\begin{array}{l}\text { In the past year, government benefitted black people too } \\
\text { much. }\end{array}$ & 1 & 2 & 3 & 4 & 5 \\
\hline 42.3 & Black people lose out on jobs because of their skin colour. & 1 & 2 & 3 & 4 & 5 \\
\hline 42.4 & $\begin{array}{l}\text { White people lose out on promotions because of their } \\
\text { skin colour. }\end{array}$ & 1 & 2 & 3 & 4 & 5 \\
\hline 42.5 & $\begin{array}{l}\text { In the past year, the media favoured black people too } \\
\text { much in terms of media coverage? }\end{array}$ & 1 & 2 & 3 & 4 & 5 \\
\hline 42.6 & $\begin{array}{l}\text { Black and white students on Potchefstroom Campus have } \\
\text { different value systems. }\end{array}$ & 1 & 2 & 3 & 4 & 5 \\
\hline
\end{tabular}

43. I will read you a number of statements. Please indicate the extent to which you agree or disagree with the following statements relating to just-world beliefs. Using the 5-point on the card, simply read out the number. Hand respondent show card. One response per line.

\begin{tabular}{|c|c|c|c|c|c|c|}
\hline \multicolumn{2}{|c|}{ Statements } & \multirow{2}{*}{$\begin{array}{c}\begin{array}{r}\text { Strongly } \\
\text { disagree }\end{array} \\
1\end{array}$} & \multirow{2}{*}{$\begin{array}{c}\text { Disagree } \\
2\end{array}$} & \multirow{2}{*}{$\begin{array}{c}\begin{array}{c}\text { Somewhat } \\
\text { agree }\end{array} \\
3\end{array}$} & \multirow{2}{*}{$\begin{array}{c}\text { Agree } \\
4\end{array}$} & \multirow{2}{*}{$\begin{array}{c}\text { Strongly } \\
\text { agree }\end{array}$} \\
\hline 43.1 & I am usually treated fairly. & & & & & \\
\hline 43.2 & $\begin{array}{l}\text { I believe that I usually get what I deserve (I get what } \\
\text { I ought to get) }\end{array}$ & 1 & 2 & 3 & 4 & 5 \\
\hline 43.3 & In my life, injustice is the exception rather than the rule. & 1 & 2 & 3 & 4 & 5 \\
\hline 43.4 & $\begin{array}{l}\text { I think basically the world is a just place (some are not } \\
\text { more favoured than others) }\end{array}$ & 1 & 2 & 3 & 4 & 5 \\
\hline 43.5 & I believe that often people get what they deserve. & 1 & 2 & 3 & 4 & 5 \\
\hline 43.6 & I am confident that justice always prevails over injustice. & 1 & 2 & 3 & 4 & 5 \\
\hline
\end{tabular}

44. I will read you a number of statements. Please indicate the extent to which you agree or disagree with the following statements relating to social dominance orientation. Using 5 points on the card, simply read out the number. Hand respondent show card. One response per line.

\begin{tabular}{|c|c|c|c|c|c|c|}
\hline \multicolumn{2}{|c|}{ Statements } & \multirow{2}{*}{$\begin{array}{c}\begin{array}{r}\text { Strongly } \\
\text { disagree }\end{array} \\
1\end{array}$} & \multirow{2}{*}{$\begin{array}{c}\text { Disagree } \\
2\end{array}$} & \multirow{2}{*}{$\begin{array}{c}\begin{array}{c}\text { Somewhat } \\
\text { agree }\end{array} \\
3\end{array}$} & \multirow{2}{*}{$\begin{array}{c}\text { Agree } \\
4\end{array}$} & \multirow{2}{*}{$\begin{array}{c}\begin{array}{c}\text { Strongly } \\
\text { agree }\end{array} \\
5\end{array}$} \\
\hline 44.1 & $\begin{array}{l}\text { It is ok if some groups in society have more of a chance } \\
\text { in life than others. }\end{array}$ & & & & & \\
\hline 44.2 & Group equality should be our ideal in society. & 1 & 2 & 3 & 4 & 5 \\
\hline 44.3 & $\begin{array}{l}\text { To get ahead in life, it is sometimes necessary to step } \\
\text { on other groups in society. }\end{array}$ & 1 & 2 & 3 & 4 & 5 \\
\hline 44.4 & $\begin{array}{l}\text { All groups in society should be given an equal chance } \\
\text { in life. }\end{array}$ & 1 & 2 & 3 & 4 & 5 \\
\hline 44.5 & $\begin{array}{l}\text { It is probably a good thing that certain groups in society } \\
\text { are at the top and other groups are at the bottom. }\end{array}$ & 1 & 2 & 3 & 4 & 5 \\
\hline 44.6 & $\begin{array}{l}\text { In getting what you want, it is sometimes necessary } \\
\text { to use force against groups different from you. }\end{array}$ & 1 & 2 & 3 & 4 & 5 \\
\hline
\end{tabular}

